\title{
Impact of E-Logistics on Warehousing Management Performance at English Biscuit Manufacturing
}

\author{
Ghulam Naseer Shah (Corresponding author) \\ Karachi University Business School \\ University of Karachi, Karachi, Pakistan \\ Tel: 92-300-7059-236 E-mail: naseershahsonu@gmail.com

\begin{abstract}
Associate Professor, Karachi University Business School
Karachi University Business School, University of Karachi, Karachi, Pakistan

Tel: 92-333-348-5884Ｅ-mail: masimku@hotmil.com
\end{abstract} \\ Muhammad Asim
}

Received: July 15, 2019 Accepted: October 20, 2019 Published: November 2, 2019

doi:10.5296/bms.v10i2.15093 URL: https://doi.org/10.5296/bms.v10i2.15093

\begin{abstract}
The main objective of the study was to determine the impact of e-logistics on warehousing management performance at English biscuit manufacturing. The study utilized quantitative research design for investigating the effects of information visibility and sharing in e-logistics, real time communication, real time forecasting decision and cost saving in E-Logistics on warehouse management performance. Quality, response, cost and productivity levels were taken as indicators of warehouse performance. Data was collected individuals currently serving English Biscuit Manufacturing to explore their perception regarding the impact of e-logistics processes on the warehousing management performance. The total number of respondents were 233 among them 85 were female and 148 were male. The results suggested that information visibility and sharing in e-logistics, real time communication, real time forecasting decision and cost saving significantly affects warehousing management performance. The need to introduce e-logistics in Pakistani manufacturing companies and training staff regarding the use of e-logistics to improve productivity was suggested in the recommendations of the study.
\end{abstract}


Keywords: E-Logistics, Warehouse Management Performance, Information Visibility, Real Time Communication, Real Time Forecasting Decision, Cost Saving.

\section{Introduction}

\subsection{Background of Study}

Managing the supply chain of a company requires a lot of planning and control so that its different stages and processes are executed in the best possible way. For this, it is important not only to evaluate the needs and resources of the business, but also to invest in Information Technology in Logistics. This measure allows gains in productivity, management and financial savings.(Bogale, 2016).

Information Technology in logistics enables managers to achieve process redesigns linked to demand, storage and distribution planning. These new streams can be more effective, delivering greater performance and results for the company. For example, using Electronic Data Interchange (EDI), or Electronic Data Interchange, facilitates and gives greater agility to an organization's electronic data transmission. This enables the reduction of human intervention in processes, helping to reduce errors.(Bogale, 2016).

E- Logistics automates the sharing of information between company or partner systems, making manual insertion of data unnecessary. This eliminates typing errors, increases the speed of data processing, and saves resources by reducing printouts to check information. Through it, it is possible to transmit different transactions, such as orders, notes, invoices, among other information (Omar, Ramayah, Sang \& Siron, 2010).

Warehouse Management System (WMS), or Warehouse Management System, is another very important technology for distribution centers. It integrates processes and technologies efficiently, in addition to recording the movements occurring in the warehouse. In this sense, it marks the place and time an action was taken and calculates the resources and time it took.

WMS automatically checks the volume of incoming products, preserving possible errors in the registry. This technology can automate bureaucratic processes, making them more fluid and dynamic (Omar, Ramayah, Sang \& Siron, 2010).

It is important to have a solution that integrates different tools and allows managing all the processes and sectors of the logistics chain. This is possible through an Enterprise Resource Planning (ERP), a system focused on the planning of company resources.It manages information from administrative and operational processes, as well as from management. Centralizing information and workflows, integrates activities across all sectors of the enterprise, and enables leaders to have effective, fast and secure access to data and reports that serve to make decisions ERP can join multiple industries, which can have shared and processed data at an organizational level, delivering information across the enterprise (Yu, Wang, Zhong, \& Huang, 2017).

There are technologies that help in selecting suppliers and negotiating contracts, making 
managers' lives easier and generating savings. E-Logistics allows the storage of information, contacts and supplier contracts in its database. There are solutions that deliver logistic performance indicators that allow to reduce the risks of the operation, besides providing strategic information for the company (Yu, Wang, Zhong, \& Huang, 2017).

Logistics today depends on the tools that information technology provides to follow the various processes that involve logistics processes. Information technology is evolving at an accelerated rate, speed and storage capacity, while generating significant cost savings by optimizing processes. Today we have several options, of information technology to assist Logistics, however it is important to know which of these suit the reality of the business. As information technology continues its evolutionary trajectory, a number of innovations emerge that influence logistics operations and improve them more and more. Thus it is important to identify how the use of e-logistics benefits warehouse management system (Arvis, Ojala, Wiederer, Shepherd, Raj, Dairabayeva, \& Kiiski, 2018).

\subsection{Objectives of Study}

1. To investigate the effect of information visibility and sharing in e-logistics on warehousing management performance at English Biscuit Manufacturing

2. To explore whether real time communication in e-logisticsimpact warehousing management performance at English Biscuit Manufacturing

3. To identify real time forecasting decision in e-logistics on warehousing management performance at English Biscuit Manufacturing

4. To find out the impact of cost savings in e-logistics on warehousing management performance at Unilever

\subsection{Statement of the Problem}

Before starting to create e-logistics, it is necessary to have a business structure and a logistics planning that has peculiarities compared to traditional commerce. Keeping a website on the internet without worrying about logistics structure means not expecting any return and perhaps having huge losses. The process of order fulfillment and product delivery (distribution logistics) is one of the main problems of electronic commerce. Thus, it is important to understand the detailed concepts of e-logistics, and how they effect in management of warehouses.

\subsection{Significance of the Study}

Electronic Logistics allows fluidity and agility in the traffic of information between customers and suppliers, global reach, reduction of order cycle time and elimination of errors, without counting plus a dozen benefits. The understanding of e-logistics and its impacts will assist companies to create new structures outside the "traditional" company, so that the concept of the dot-com organization can be totally absorbed by the organizations, and that new processes suggested can extract the full potential of the trade electronic and 
Internet-based technologies.

\subsection{Research Question}

RQ1 Does information visibility and sharing in e-logistics influence warehousing management performance at English Biscuit Manufacturing?

RQ2 To what extent does real time communication in e-logistics impact warehousing management performance at English Biscuit Manufacturing?

RQ3 Does real time forecasting decision in e-logistics on warehousing management performance at English Biscuit Manufacturing?

RQ4 Does cost savings in e-logistics effects warehousing management performance at Unilever?

\subsection{Research Hypothesis}

$\mathbf{H}_{1}$ : Information visibility and sharing in e-logistics does not impact on warehousing management performance at English Biscuit Manufacturing

$\mathbf{H}_{2}$ : Real time communication in e-logistics does not impact on warehousing management performance at English Biscuit Manufacturing

$\mathbf{H}_{3}$ : Real time forecasting decision in e-logistics does not impact on warehousing management performance at English Biscuit Manufacturing

$\mathbf{H}_{4}$ : Cost savings in e-logistics does not impact on warehousing management performance at Unilever

\subsection{Conceptual Framework}

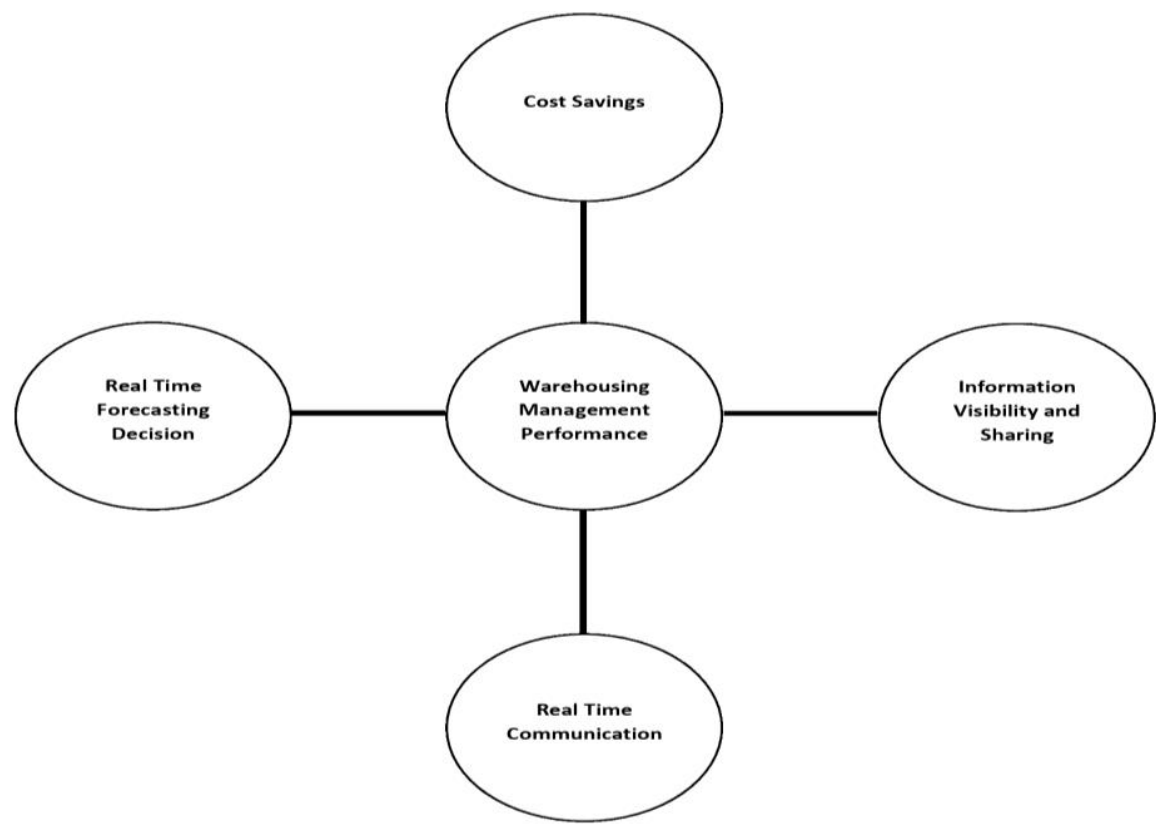




\section{Literature Review}

\subsection{Definition of Logistics}

Logistics means accounting and organization and is a term of Greek origin. Logistics also comes from the French "logistique" which means an art that deals with the planning and realization of various designs, much used during the wars. Logistics is also used as part of algebra and mathematical logic (Arvis, Ojala, Wiederer, Shepherd, Raj, Dairabayeva, \& Kiiski, 2018).

Logistics consists of a series of actions that must be performed to ensure that a product reaches the consumer, and that includes everything from obtaining the raw materials for the production of the product to its production and distribution. Logistics will then study, analyze and seek to put into practice the best solutions for transportation, storage , manufacturing and distribution of products to the market, taking into account quality, time and cost.(Arvis, Ojala, Wiederer, Shepherd, Raj, Dairabayeva, \& Kiiski, 2018).

With this we can define logistics as the activity that aims to organize and account for the materials and products from its origin as raw material until its final destination, the final consumer. And in this sense, its objective is to make available to consumers the product they want, in the right quantity, at the right time and at the best point of sale, and all this in order to generate the lowest possible cost and consequently the highest profit (Christopher, 2017).

Among the various activities that comprise logistics, we can generally highlight some of the main ones, such as: purchase order processing; the management of raw materials and products; packaging definition; the best means, schedules and routes for the transportation of products; storage and inventory control, and so on (Christopher, 2017).

\subsection{Definition of E-logistics}

E-Logistics is a term used in e-commerce. It can be defined as an essential component of e-commerce, comprising the entire logistics chain that can be composed of:Reception and conditioning of products; Stocking; Picking (moving of products for the preparation of the request) and intervention of the carriers taking delivery;

These steps should be inserted into order tracking tools, allowing better control of the different operations, and giving customers real-time information of the stage in which the product is purchased (Mangiaracina, Marchet, Perotti, \& Tumino, 2015)

There must be perfect synchronization with suppliers in the supply process cycles required to replenish the stocks of products sold by the e-commerce site. This logistic synchrony can be obtained more easily in the measurement from the computerization of these processes, generating speed in the exchange of information and resulting in the reduction of terms and costs of acquisition of the products, as well as in the reduction of the cost of the inventories. In practice, whenever the stock level of a given product reaches the minimum quantity.A purchase order is systematically triggered and sent to the supplier via the internet 
or EDI, initiating the stock replenishment process. This cycle ends only when the supplier delivers the product to the customer and there is an update of the inventory control and e-commerce systems (Mangiaracina, Marchet, Perotti, \& Tumino, 2015).

\subsection{Evolution of IT in the Field of Supply Chain}

The evolutionary line indicates how the functional integration of the various areas of the supply chain has occurred, is nowadays Integrated Logistics to meet the demands of materials and products, which goes beyond the limits of the company, connecting the logistics functions of the whole chain from the raw material supplier to the final consumer (Mangiaracina, Marchet, Perotti, \& Tumino, 2015)

The evolution presented in this diagram can also be seen as the change of vision from internal logistics to external logistics, that is, the focus shifted from productivity, lead times and logistics costs to the relationship between companies and other members of the supply chain.

Logistics and transportation have always been basic to the development of peoples. Keeping due proportion and reality, the policy (what to do?) And strategy (how to do?) Are constituents of any evolution? Another important consideration regarding the politics and strategy of many organizations had its origin in the Industrial Revolution. The technologies developed in this period and its application powerfully influenced the functioning of the organizations and gave steam power in the production and that soon replaced the human effort allowing the appearance of factories and industries (Yu, Wang, Zhong, \& Huang, 2016).

The logistics function has several concepts, but none can fully define their actions, since logistics is a living and evolutionary science. The word Logistics comes from the Greek "logistikós" which was the denomination given to the art of calculating, meaning practical calculation as opposed to theoretical arithmetic. As a science, logistics began to be employed from the nineteenth century and was consolidated at the beginning of the twentieth century with influence from the mainstream of administrative theories, mainly from Cientifica, whose main name is Frederick Winslow Taylor (1856-1915).

As pillar of Logistics, the Strategy, which by etymology is a Greek term "strategists", meaning the art of the General, a military reference to the past when the task of making war was a direct responsibility of the military chiefs, has a great influence on the sector's bias. People have been planning and managing projects since the beginning of time. Throughout the history of humanity, the concept of strategy has evolved assuming the global dimension in World War II. The 1950s mark the evolution of the traditional concept of strategy from the military to the business world. Organizational Strategy, in a simple way, can be conceptualized as the path to the achievement of organizational goals, oriented towards the future of the organization and oriented towards the long term (Yu, Wang, Zhong, \& Huang, 2016).

In the field of influence of the currents of the study of the Administration listed in the 
development of the logistics throughout the times, we can affirm that some theories of the administration had and have great weight in the formation and evolution of the logistic field. The Scientific Administration, for example, exerts a significant influence with the Taylorist model in the search for efficiency. The Study of the best way to perform the tasks "The Bast Way", study of times and movements, standardization and increase of production by means of Cartesian methods, training of workers, division of labor and reduction of costs and maximization of profits. Below are the main theories of Administration with influences in the logistic field (Yu, Wang, Zhong, \& Huang, 2016).

\subsubsection{The Theory of Bureaucracy}

This chain, which has Max Weber as its representative, also with a strong influence on the methodology developed in the logistics systems, has as main exponents in logistics the Formalism of Communications, Standardization of Routines and procedures, hierarchy of authority, Recruitment and selection and flat visibility of operation. In this process we have defined bases of Specialization, Predictability and Rationality.(Weber, 2013)

\subsubsection{Classical Theory}

Having as absolute reference Henri Fayol, the Classical theory has fundamental importance in the composition of supply chains and logistic system, since it is attached to basic concepts of efficiency taken into account until the present day as the increase of productive efficiency with focus in the structure, departmentalization and functioning of organizations.(Peaucelle \& Guthrie, 2015).

\subsubsection{Contingency Theory}

With emphasis on the environment and technology, contingency theory is one of the pillars of logistics, since it sees the organization as an organic system and evaluates the technological, legal, political, economic, demographic, ecological and environmental conditions. organizational environment as an open or closed system.

Entering the evolution of market needs, we realize that the technological sector, competence of Information Technology, has exerted a strong influence in the improvement of the different projects and logistic processes. This technological evolution provides advantages for logistics operations, which are making them faster, more reliable, less expensive and more efficient. The IT industry has been undergoing a significant transformation, creating ever more frequent cycles of change and providing its users with greater ease of acquisition and access to computer resources, facilitating the decision-making process, integrating information among the activities that comprise the value chain of an Organization (Peaucelle \& Guthrie, 2015).

Logistics currently emphasizes strategy and is a differentiating element in business, identified as the last frontier in which new competitive advantages can be exploited. With the evolution of Integrated Logistics, the emphasis on globalization and the advancement of information technology, the Supply Chain Management (SCM) concept emerges. 
While Integrated Logistics represents an internal integration of activities, SCM represents its external integration as it extends the coordination of material and information flows to suppliers and the end customer. Managing the chain as a whole can provide a number of ways in which you can increase productivity and contribute to cost savings, as well as identify ways to add value to products. Understanding customer / consumer expectations is fundamental for good structuring and good performance of the logistics system (Giuffrida, Mangiaracina, Perego, \& Tumino, 2017).

Even with all the technological and management evolution that has been achieved to date, the logistics sector, mainly represented by logistics operators and carriers, has been forced to re-evaluate costs in a more micro-fashion, as the market is becoming more demanding and opening new ones concepts of bids and competitions, the well-known BIDs , of English - Bid, Offer, etc.

The logistics sector grows daily with the demands of production, distribution and consumption, leaving the market to study the movement of demands to know what the future awaits (Giuffrida, Mangiaracina, Perego, \& Tumino, 2017).

\subsection{Information Visibility and Sharing (IVS)}

The internet has revolutionized the way individuals express their opinions, talents, and develop interactions not only in the personal field. Everything we do is being seen and that, today, can turn into job opportunities. Yes, companies have seen in the social networking arena a way to develop their marketing, take strengths to potential customers, and reach those who initially did not even look for a solution that the business offers. Some on this journey can even recruit good collaborators for their team (Xu, Cheng \& Huang, 2015).

In this context, some platforms have been in the game for a longer time and are well-liked by individuals not only in their personal lives, but also in terms of use by companies such as Facebook, Twitter, Instagram, and YouTube. However, one tool stands out as an exclusively professional channel: LinkedIn. For this reason, it deserves special attention on the part of the entrepreneurs (Xu, Cheng \& Huang,2015).

\subsection{Real Time Communication (RTC)}

To date, several attempts have been made to create hybrid and abstract platforms enough to allow real-time communication of applications among the many different types of devices that exist. Some recent efforts that explore such a concept more focused on the mobile universe and IoT ( Internet of Things ), such as Tizen or Android itself, bring with it the possibility of developing towards a range of different types of hardware, sizes and purposes (TVs, smartphones, tablets, wearable, smart watches, glasses, etc.) (Zhang, Pratap, Huang, \& Zhao, 2017).

But this whole technology apparatus involves a considerable complexity, especially if we take into account the number of device manufacturers, their own specifications, the hardware and firmware models, and above all the way the web communicates with all this, a as it will 
be the starting point for this much-desired standardization (Zhang, Pratap, Huang, \& Zhao, 2017).

Everything on the web works (and should) in a standardized way. The W3C specifications define the directions that a given technology follows in this universe, as well as its death to the detriment of the birth of a better one. At the same time, companies such as Google, Mozilla, Facebook, Twitter, among others, directly influence such directions by launching new features for their browsers, submitting new specifications for $\mathrm{W} 3 \mathrm{C}$, creating new front-end frameworks (ie AngularJS, Bootstrap, etc.) as well as the centralization of their development communities.

Now away from the realities of the mobile world, imagine a reality where your TV, your smartphone, your refrigerator and your computer can communicate without all these barriers, in real time, on one platform. Imagine being able to share all kinds of data, videos, chats, and messaging between these devices in an integrated and fast way. It may seem very futuristic, but we already have a technology that tries to embrace this ideal: WebRTC (contraction of Web Real Time Communication).

\subsection{Real Time Forecasting Decision (RTFD)}

More demanding consumer wants fast delivery and in order to serve it efficiently, the logistics must be well prepared. The delivery forecast is directly linked to customer satisfaction with the buying experience and is a consequence of a good sales action performed by the company. For logistics, working together with the sales sector is of vital importance for the planning of operations. After all, a sale only takes place when the product is delivered to the customer.

There is no way to talk about delivery forecasting without relating it to inventory. The lack of goods means loss of sales, and the excess represents stopped money. Here comes the demand forecast, usually based on specialized analysis and sales history of the company to try to define the place, time and quantity that a product will be requested by the customer, in order to serve it efficiently (Zhang, Pratap, Huang, \& Zhao, 2017).

In fact, demand forecasting is the basis for all strategic and planning decisions in a supply chain and includes the production, sales, and finance areas of each company. This is a very important variable for the management of inventory and brings with it several aspects, such as the smarter use of the physical space, the reduction of operational costs, improvements in processes and the guarantee of competitiveness in the market.

This view needs to be developed by sales professionals because often the problems that logistics face in forecasting the delivery of goods come from failures in the beginning of the process, order placement and forecasts. In most cases, integrated software can help you quickly identify the highest turnover products and take preventive action on replacements, ensuring delivery forecast.

In large urban centers, what is gained in the vicinity of stops is quickly lost with delays 
caused by congestion. To minimize and overcome this effect, the forecast of delivery must have a good planning in all phases of the commercialization of products.

\subsection{Cost Savings (CS)}

One of the challenges of business management is cost reduction. One of the solutions to this goal is the automation of accounting. Many companies view accounting as a complex activity, requiring skilled and resource-intensive staff. However, there is a solution to make this task more accessible: implement management software (Zhang, Pratap, Huang, \& Zhao, 2017).

Information technology has assumed an increasingly important role in business management. Management software will help automate accounting tasks and consequently reduce costs. When implementing a management system, accounting become a task accessible to anyone. This investment makes business management simpler and less labor intensive. This technology will allow you to not have to hire a specialized team or sub-hire an outside company for this task. This results in cost savings for your business!

In a consulting process, especially in the Business Diagnostics or Hemogrammes stages, it is very common for people to think they know a great deal about Strategic Cost Reduction Management. But the reality we see is quite different from that. We always have to keep in mind that reducing costs or expenses, anyway, is the easiest process in the world. In fact, we see a lot of that out there: companies without cost management, cutting in a bewildered way, without focus, which often ends up decreasing the level of quality in customer service or even paying dearly and going back on previous costs (Yu, Wang, Zhong, \& Huang, 2017).

\subsection{E-logistics to Improve Warehouse Management}

The development of the receiving and shipping operations followed some trends, among which we have: new sizes (length and width) of goods transport trucks, just in time policy, computers, bar codes and GPS and the use of new equipment for unloading and loading. The Just in Time policy is a system that allows you to schedule receipt of articles on the dock and at that time replenish the workstation or reserve it for immediate use. This policy has made it possible to reduce the inventory of available safety stocks for immediate use and to concentrate more resources on dock receiving and shipping locations for warehouse and distribution operations rather than typical storage locations (Zhang, Pratap, Huang, \& Zhao, 2017).

The carriers saw their height and width increased, which allowed for the transportation of two more pallets, which in turn resulted in the increase of the seats for the carriers in the warehouses, the width of the door, the quayside shelters and the preparation areas on the piers, among others (Yu, Wang, Zhong, \& Huang, 2017). The use of computers, bar codes and GPS has revolutionized reception and dispatch, with improvements: document preparation, correct identification of customers and products, scheduling of activities by both the employee and equipment and online bank transfers. With the use of hand scanners and scannersfixed (Figure 1) it is possible to ensure the correct identification of products and that this 
information is available online. This new technology has made it possible to improve: inventory identification, product flow control, more efficient internal transportation, accurate assignment of order forms and carrier manifests. With the use of GPS (Figure 2) it was possible to improve the use of carriers and the productivity of workers and equipment. This technology based on radio frequencies consists of marking through them in a carrier, workstation and monitoring center, allowing to know the exact position of the carrier at any given time.

Trends in new unloading and loading equipment include dock levelers, automatic unloading and loading systems, mobile warehouse equipment and conveyor belts. Its objectives are: to increase the flexibility of reception and dispatch departments in the handling of various types of carriers and improvements in safety, product flow and worker productivity in departments. It can be concluded that in the future there will be a reduction in the number of employees and workspace that is assigned to the receiving and dispatch operations, but there will be an increase in the number of companies implementing the cross-docking operation (Zhang, Pratap, Huang, \& Zhao, 2017).

\subsection{Warehousing Management Performance (WMP)}

Nowadays, with the increasingly competitive business environment, information technology, when well used, becomes a strong differential among companies for the pursuit of excellence in customer service. Thus, more and more companies are looking for alternatives to facilitate the management of their activities, in order to increase control and obtain accurate information that can actually speed up decision making and, consequently, improve the level of service provided.

The evolution of information technology has transformed operations management and logistics. As examples, we can mention the use of bar code, EDI (electronic data interchange), RFID (Radio Frequency Identification) and Fleet Tracking with GPS (Global Positioning System) technology. All these technologies serve not only to increase the speed of information flow, but also to improve the accuracy of information.

Specifically, in the specific case of warehouses, warehouses and large distribution centers (CD), the management systems known as WMS (Warehouse Management System) can be considered a good alternative to optimize the storage activity, since they are looking for ways to optimize spaces and organize the flow and distribution of products. WMS is a warehouse and / or CDM system that optimizes all operational (material flow) and administrative (information flow) activities within the warehousing process, including such activities as: receiving, inspecting, addressing, storing, -parking, packaging, loading, shipping, document issuing and inventory control (Zhang, Pratap, Huang, \& Zhao, 2017).

WMS arose from the need to improve the flow of information and materials within a warehouse, warehouse or $\mathrm{CD}$, with the main results being cost reduction, improvement in operation and increase in the level of service provided to customers (Figure 1 ). The optimization provided by WMS allows for increased accuracy of inventory information, 
speed and quality of $\mathrm{CD}$ operations, and productivity of personnel and equipment. This has become possible due to the emergence of new information technologies in both hardware and software.

Warehouse management systems suggest the evolution of old warehouse control systems or Warehouse Control Systems (WCS). Some additional functions were being aggregated as WCS evolved from a simple control system to a more complex system, capable of making suggestions or performing calculations.

Until the mid-1970s the WCS only had the ability to control the inbound and outbound transactions in inventory and the respective write-off of such transactions against requests from suppliers and customers. From then on, the first address control systems appeared, which became concerned with the location of the product in an "address" in the warehouse or $\mathrm{CD}$. This evolution allowed the products to no longer have fixed locations and to be stored in different areas of the CDs according to availability, and with this it was possible to increase the storage density (Yu, Wang, Zhong, \& Huang, 2017).

The main difference between WMS and WCS is that the latter is not a warehouse manager, thus differing from WMS in some respects. WCS does not offer a variety of reports to assist in the management of activities; no hardware flexibility; the customization is limited to the change of fields and names and its installation cannot be done in a modular, only integral way. The counterpart to all of these negative aspects is that it provides optimal monitoring and control of activities (if limited to control) at a reduced cost of software and hardware required for its implementation.

One of the benefits generated by the WMS is the optimization of space in the storage area. The system has as one of its functions the suggestion of the best place to store a particular product at the time of its receipt, thus preventing the operator from scrolling the entire CD in search of an available place to store (Zhang, Pratap, Huang, \& Zhao, 2017).

A WMS enables operational optimization by increasing productivity, optimizing spaces, and improving resource utilization (moving and stocking equipment). These benefits are due to the following points, as presented in Banzato (1998):

\subsection{Warehouse performance Indicators}

We all know that it is not possible to manage what is not measured and, without that care, a transport company will jeopardize its success. The best solution in this case is to establish good fleet management. However, many managers believe that just keeping processes running synchronously is enough. However, a really efficient fleet management goes way beyond that. To find out if they are in accordance with the plans drawn up and use them to make projections of future results. For this, you will need to use the right Key Performance Indicators (KPIs).

2.9.1 Quality Indicator (QI) 
Quality indicators evaluate the quality (or lack thereof) in these internal processes.Accuracy of receipt: evaluates if errors or faults occur in the receiving process. The cost is low and the process is fast if losses, errors and malfunctions occur. The Receiving Accuracy indicator is calculated as the percentage of errors on the total of items received.

Precision index in the separation: in the same way as the previous one, this index is calculated as the percentage of errors on the total of separated units. Loading accuracy index: this indicator is also calculated as the percentage of errors on the total of units loaded (Zhang, Pratap, Huang, \& Zhao, 2017).

These are just a few examples of performance indicators for the storage and internal handling industry. They can (and should) be tailored to measure processes relevant to each company. Check out other examples of indicators in the related topics below in the Uncomplicated Logistics.

\subsubsection{Response Time Indicator (RTI)}

The virtual shopkeeper, when he starts to grow, finds himself at a crossroads: he needs to scale the business, better serve the customer, sell his products in physical and virtual stores, and publish stocks in marketplaces and so on. At first, it does all this manually, using 1 or 2 non-integrated systems, transferring information back and forth manually or keeping it in multiple worksheets. It works, but it realizes that it needs to automate its processes or it will end up going crazy - and leaving its team crazy too - or that all the profitability will be invested in hiring an increasing team.

It is quite common for the retailer to complete the supplier evaluation process with the need to hire, on average, 3 to 4 different company systems to compose the scenario that meets the supplier, and often need to hire companies that exchange information. In a brilliant article published here at the same node E-commerce Brazil, Marcelo Linares showed with good humor the absurd comparison of a bakery being managed as an e-commerce. It addresses some very interesting items, but for didactic purposes (and to stay only on the theme that I master) we will approach, broadening the scope a little, only the challenges of the scenario involving systems.

When you have to deal with more than one system in your operation, the retailer is faced with problems of a new type. Remember, did you think all those tools would be the solution to your problems? Yeah. In some scenarios, such as small and medium-sized businesses, commercial documents are not electronically exchanged because of the low volume of documents or resources available. A possible solution to address this problem is the deployment of a Web Portal. The solution is aimed at those suppliers with a medium or low number electronic invoice issuance that allows you to enter the required data through a web form on the portal itself.

EDICOM makes it possible for large companies to enable an online system to publish their purchase orders so that their trading partners can generate and send commercial documents 
such as: shipping notes and invoices in order to be integrated in the ERP in the process reception. The portal allows the implementation of a bidirectional flow, being possible to send purchase orders through the solution to their suppliers automatically through the ERP. In this way, purchase orders act as base documents allowing the supplier to re-use the originating information of the order to issue the invoice. (Gunasekaran McGaughey Ngai \& Rai 2009).

To put it into practice, a large company will provide its partners with a completely free portal. The portal is accessible via the web, by user and password. In the platform are configured the documents to be exchanged between the main actors, through validation mechanisms that guarantee that the registered information is the one required by the destination. The vendor receives an order and connects to the portal. By means of preconfigured models, the form with the data of the document and send is completed. The document is processed and sent via EDI in a standard format to integrate it with the recipient's ERP.

\subsubsection{Cost/Financial Indicator (CFI)}

For good financial management, the use of financial indicators is especially useful. And among them, some are considered more important to know how the business is. So in today's post we present 5 of them, in addition to their calculations and how to use them properly. (Arvis, Ojala, Wiederer, Shepherd, Raj, Dairabayeva, \& Kiiski, 2018).

\section{Gross revenue}

Gross billing is an indicator it is simple to track, but it serves as the basis for many other analyzes. To keep up with it, you just have to add up all the resource inflows in the company within a certain period.

Basically, just add up all the sales made or all the monthly payments paid by the customers. If a store sold in a month, 200 pieces at $\$ 100.00$, for example, the billing is given for $\$$ $20,000.00$.

Thus, the formula is:

\section{Gross sales $=$ number of sales $\mathrm{x}$ unit price}

Initially, it can be compared against the expected value. If the expectation, through relevant analysis, was $\$ 30,000.00$, then there is a probable indication that something harmful to the billing occurred with the business (Arvis, Ojala, Wiederer, Shepherd, Raj, Dairabayeva, \& Kiiski, 2018)

\section{Profitability}

Profitability is one of the most important financial indicators because a business can have high revenue, and not be profitable. So, since it is from the profit margin that the business holds, expands and pays its owners, it is worth keeping an eye on that indicator.

It is calculated as follows: 
Profitability $=($ gross profit $/$ revenue $) \times 100 \%$

If of the $\mathrm{R} \$ 20,000.00$, collected in the previous example, $\mathrm{R} \$ 12,000.00$ corresponds to the profit, that is to say that there is a profitability of $60 \%$. If the ratio is given by net or operating profit, it is operating margin.

In this case, it is worth thinking that of the $\mathrm{R} \$ 20,000.00, \mathrm{R} \$ 8,000.00$ correspond to the operating profit. Thus, profitability or operating margin is given by $40 \%$. In fact, there is no unique number that indicates excellent profitability - in fact, the higher the value found, the better. A negative figure, on the other hand, indicates that the business is spending more than it earns, even with sales.(Arvis, Ojala, Wiederer, Shepherd, Raj, Dairabayeva, \& Kiiski, 2018).

\section{Contribution margin}

The contribution margin, in turn, indicates in relative way how much each product or service contributes to the company's profit. And, for it to be calculated, the following formula is used:

Contribution margin $=[($ sale value - fixed and variable costs $) /$ sale value $] \times 100 \%$

For calculation purposes, let's take into account a certain product, which costs $\$ 100.00$. Of this amount, $R$ \$ 10 goes to the acquisition of $R \$ 40.00$ for various taxes and $R \$ 10.00$ for the payment of other expenses.

Thus, the contribution margin is given by:

Contribution margin $=[(100-40-10-10) / 100] \times 100 \%$

Contribution margin $=40 \%$

So, this means that in the case of this product, every $\mathrm{R} \$ 1.00$ invested there is a contribution of $\mathrm{R} \$ 0.40$ to the profits of the company.(Christopher, 2017).

Current Liquidity

Knowing the immobilization of business resources is also fundamental for making decisions and for understanding how your financial situation is going. After all, having too many resources depleted the business's competitive advantage, and it makes you lose good chances.

To prevent this from happening, it is recommended to keep up with current liquidity. This indicator is short-term and shows, within a certain period of time, how immobilized the assets are.

To calculate it, we use the formula:

Current assets $=$ current assets $/$ current liabilities

In this case, current assets correspond to all resources, such as accounts receivable, cash and investments. Current liabilities correspond to accounts payable, fixed costs and other 
expenses. So if in a given month the company has current assets of R \$50,000.00 and current liabilities of $\mathrm{R} \$ 25,000.00$, for example, current liquidity is 2 or $200 \%$ - which indicates that the business has many resources available. However, in another example, if the assets correspond to $\mathrm{R} \$ 50,000.00$ and the liabilities to $\mathrm{R} \$ 75,000.00$, then the current liquidity is of 0.67 approximately. With this, the company will need to have cash resources to fulfill its obligations.(Christopher, 2017).

\section{Average Ticket}

The average ticket refers to customers and is especially important to understand both business performance and customer behavior. Basically, it corresponds to the average amount spent by customers within the finished period of time.

The calculation can be done either individually or collectively, as follows:

average ticket $=$ gross sales $/$ number of sales

Therefore, a customer who bought R \$ 150 in one month, R \$ 220 in the second and R \$ 230 in the third month, for example, had a total cost of $\mathrm{R} \$ 600.00$ in the quarter. Thus, your average ticket is given for $\$ 200.00$. Already for the calculation of collective way, just think of a business that had gross sales of $\$ 200,000.00$ and about 500 sales. With this, the average ticket per customer is $\$ 400.00$ (Christopher, 2017).

Tracking this indicator is important because to increase business revenue, you can increase both the number of sales and the average ticket - that is, make people spend more and the level of this indicator will be good or bad depending on the business. If the average ticket is $\$$ 400.00 and the products cost an average of $\$ 300$, there is an indication that customers are making smaller purchases or are not returning. If the products cost around R \$ 100, this same average ticket indicates a successful strategy. (Christopher, 2017).

Finally, as we have seen, the financial indicators that allow us to monitor the health of the company include gross revenue, profitability, contribution margin, current liquidity and average ticket. So with proper analysis of them, for sure, the business is favored - just like your success!

\subsubsection{Productivity Indicator (PI)}

KPIs are responsible for generating high quality products and services, in less time and with less expense - through structured processes developed by qualified people. The productivity indicators are obtained from comparative parameters between what was generated by the organization (product or service) and what was used in terms of resources for its production. With this result in hand, it is possible to precisely define the amount of input that has been spent on the production of each unit or service provided (Christopher, 2017).

For the indicators to present real results about the company, it is necessary to know in depth all the organizational activities. For example, it would be pointless for an employee of the company to do training without the manager being able to exploit the result of that training, 
transforming the knowledge acquired by the employee into resources usable in other company processes. But how do you measure what really matters in your business? Below are 8 indicators that allow you to evaluate your company's productivity. (Mangiaracina, Marchet, Perotti, \& Tumino, 2015).

Operational excellence

Measures the efficiency of the processes used by the company. Let's assume that the company in question is a call center and appointment of a hospital. Items such as the average time of patient care, deadline for delivery of test results, and use of the infrastructure are efficient or require improvements (Mangiaracina, Marchet, Perotti, \& Tumino, 2015).

What if we were in an industry? Issues such as units produced without failures per hour, capacity to meet the demand and efficient use of resources would be the target of the measurement of productivity indicators. By finding errors or spaces for improvement, it is possible to eliminate failures, increase quality and, consequently, raise the productivity indicators of any activity.

Ability to innovate

The investment in innovation deals with the capacity that the company has of bringing significant evolutions to the productive processes. A survey carried out by the IPEA of 2013 shows that companies that establish innovative parameters present productivity indicators $20 \%$ higher than those that do not invest in innovation, either by lack of interest, lack of funds or simple ignorance. In practice, innovative companies tend to invest more in technology, in personnel (qualification) and in production processes. This opens space for more competitiveness, in addition to attention to the oscillations of the market (Mangiaracina, Marchet, Perotti, \& Tumino, 2015).

So much so that other IPEA research indicates that innovative companies are up to $30 \%$ higher than others and pay up to 50\% more for workers than companies that do not invest in innovation. The same study reports that companies that value innovative capacity are also more likely to become exporters, reaching optimum levels of productivity and competitiveness in the market.

Sustainable production

This indicator involves four dimensions: environmental, economic, social and institutional, and aims to verify the company's ability to operate without adversely affecting the environment with which it coexists. Implementing sustainable actions involves both measures such as reduction of production costs (from products and services) to the reduction of waste released into the environment. Among the most effective actions of sustainable companies is Digital Transaction Management or simply DTM (Giuffrida, Mangiaracina, Perego, \& Tumino, 2017).

Including digital transformation in projects involving cost reduction allows stacks and piles 
of paper to be replaced by electronic documents and there is a considerable reduction in pollution caused by paper industries. In this sense, in addition to modifying a process considered costly by a more economical one, the electronic signature reduces storage spaces and teams involved, acting directly in the optimization of document flow and process productivity. Just so you have an idea, you are made about 1 billion copies a day around the world (Giuffrida, Mangiaracina, Perego, \& Tumino, 2017).

\section{Turnover rate}

The term turnover looks complex, but the equation is relatively simple. Just add the number of layoffs and the number of admissions divided by two, divided by the total number of employees. The result allows the company to check the employee turnover rate and to evaluate where the problems are to be corrected. The turnover index, along with the absenteeism index (absences at work), is a useful tool to implement an employee satisfaction project. In addition, it allows the company to avoid costs with termination of employment contracts, recruitment and selection expenses, with training, adaptation and other variable expenses.By investigating the reasons that lead to turnover, the company can implement training and development programs that, in addition to contributing to the engagement of professionals, contribute to increased productivity, after all, skilled people are better able to do a good jobn(Giuffrida, Mangiaracina, Perego, \& Tumino, 2017).

\section{Investment in qualification}

And since we speak of training and increased productivity, qualified teams translate into quality products and services, that is, the higher the qualification of your team, the better the products and services, reflecting the satisfaction of the final customer.This means that by investing in training you are applying resources to make your company more competitive.

A professional who receives the proper training performs his tasks in less time and with higher quality. The consequence is more deliveries within the same working period, that is, higher productivity.

This same person, when properly oriented about the company's processes, consumes fewer resources, such as electricity, office supplies and raw materials, for example. The result is only one: reduced production costs and increased business profitability $(\mathrm{Xu}$, Cheng \& Huang, 2015).

\section{Flexibility index}

Flexibility can be measured based on the adaptation levels that a company obtains in response to changes and demands generated by the oscillating market. A company that has the power of flexibility is more prepared to respond to market changes and has greater adaptability, a large market differential that can mean the difference between staying competitive and stagnating in business (Xu, Cheng \& Huang, 2015).

Production control 
Frequent monitoring of processes is essential to identify bottlenecks on the one hand and positive attitudes on the other. Quantitative and qualitative measurement of production is a way of ensuring control of what is being produced and, together with this, verifying where to invest more, less or not to invest (Xu, Cheng \& Huang,2015).

Let's imagine a publisher of technical books that produces 1,000 units a day. To ensure that final consumers are satisfied, there can be no grammatical errors in the contents. Nor any printing errors, so strict quality control is essential. If, in quality control, it is verified that for every 1,000 units produced, 10 come out with failures, it is necessary to understand what causes the problem and eliminate the factor, in order to guarantee maximum capacity of production and delivery, as well as the profitability of the business.

\section{Success in Sales}

To determine if the sale of a product or service was successful, it is important to establish the relationship between the winning rate in the negotiations, ie the number of sales effectively closed by the company and how many opportunities were opened in a given period.

The sales team needs to stay in tune with the other sectors and wear the company shirt. Thus, it is possible to detect frustrated sales attempts, at which point the sale did not materialize and solve the bottlenecks (Yu, Wang, Zhong\& Huang, 2016).

\section{Strategy}

The correct execution of business strategy also contributes to improving productivity indicators. If the organization plans to expand the business through the opening of a subsidiary, for example, the productive capacity is increased.

Another point where strategic indicators influence business productivity is in hiring employees. By the time the company defines exactly the professional profile required for a given function, it is ensuring that the contracted person will effectively contribute to the company's results. In this sense, it must be borne in mind that the measurement of results is not done in isolation. Just as productivity indicators influence other performance factors, so does the opposite (Yu, Wang, Zhong\& Huang, 2016).

\section{Competitiveness}

Finally, we have the competitiveness indicators, which reveal how the company is positioned relative to its competitors (Zhang, Pratap, Huang, \& Zhao, 2017).

\section{Methodology}

\subsection{Research Design}

The study was based on the quantitative research methodology in impact of e-Logistics on Warehousing Management Performance at English Biscuit Manufacturing companies. The e-Logistics was the independent variable of the study which was defined in terms of Information Visibility and Sharing (IVS), Real Time Communication (RTC), Real Time 
Forecasting Decision (RTFD) and Cost Savings (CS). The Warehousing Management Performance (WMP) was the dependent variables based on the scales of Quality Indicator (QI), Response Time Indicator (RTI), Cost/Financial Indicator (CFI) and Productivity Indicator $(\mathrm{PI})$

\subsection{Research Instrument}

The research instrument is a device or tool, which a researcher employs to gather data. There are multiple ways to gauge data such as interviews, psychological tests, and questionnaires. The data of this study is collected using a questionnaire as a research instrument. The questionnaire from Bogale (2016) and Omar, Ramayah, Sang \& Siron (2010) was employed

to obtain the responses. Questionnaire was based on Likert scale. There were 14 items for measuring the independent variable e-Logistics 14 items and 17 items to measure dependent variable warehouse performance. The questionnaire on the whole consisted of 32 items in total.

\subsection{Population}

The population of the study consisted of all employers from at English Biscuit Manufactures.

\subsection{Sample}

Simple random technique was used since it gives every participant and equal chance of being selected. The data was gathered from the individuals currently serving English Biscuit Manufacturing to explore their perception regarding the impact of e-logistics processes on the warehousing management performance. The total number of respondents were 233 among them 85 were female and 148 were male.

\subsection{Data Collection}

The researcher adapted the questionnaire in order to gather the data on the study variables. The questionnaire was converted into e-questionnaire by utilization the google form application. The link to the questionnaire was send to the females working in health sector. The employees respondents from English Biscuit Manufacturing were contacted and the questionnaire was sent via email.

\subsection{Data Analyses}

The research employed the statistical software SPSS which is an abbreviation for Statistical Package for Social Sciences to analyze the data. Researcher used descriptive statistics to describe the set of data at initial stage. Afterwards Regression, ANOVA analysis and correlational tools were employed to instigate the relationship between independent and dependent variables.

\section{Results and Findings}

\subsection{Variables}




\section{Macrothink}

4.1.1 Dependent Variable

- Warehousing Management Performance (WMP)

- Quality Indicator (QI)

- $\quad$ Response Time Indicator (RTI)

- Cost/Financial Indicator (CFI)

- $\quad$ Productivity Indicator (PI)

4.1.2 Independent Variable

- $\quad$ E-Logistics

- Information Visibility and Sharing (IVS)

- $\quad$ Real Time Communication (RTC)

- $\quad$ Real Time Forecasting Decision (RTFD)

- $\quad$ Cost Savings (CS)

\subsection{Research Hypothesis}

H1: Information visibility and sharing in e-logistics does not impact on warehousing management performance at English Biscuit Manufacturing

$\mathrm{H} 2$ : Real time communication in e-logistics does not impact on warehousing management performance at English Biscuit Manufacturing

H3: Real time forecasting decision in e-logistics does not impact on warehousing management performance at English Biscuit Manufacturing

H4: Cost savings in e-logistics does not impact on warehousing management performance at Unilever

\subsection{Descriptive Analysis}

The data was gathered from the individuals currently serving English Biscuit Manufacturing to explore their perception regarding the impact of e-logistics processes on the warehousing management performance. Table 1 displays the characteristics of the respondents in terms of their gender, age group, and educational qualification. From this perspective, the total number of respondents were $233(\mathrm{n}=200)$, among them 85 (36.5 per cent) were female and 148 (63.5 per cent) were male. On the other hand, a large number of respondents were of the age group between 18 and 27 (131 = 56.2 per cent). Similarly, a large number of respondents were possessing bachelor's degree $(84=36.1$ per cent $)$ and Master's degree $(64=27.5$ per cent $)$. 
Table 1. Descriptive Statistics of Respondents

\section{Gender}

\section{Frequency Percent Valid Percent Cumulative Percent}

\begin{tabular}{|c|c|c|c|c|}
\hline Female & 85 & 36.5 & 36.5 & 36.5 \\
\hline Male & 148 & 63.5 & 63.5 & 100.0 \\
\hline \multicolumn{5}{|c|}{ Age } \\
\hline $18-27$ years & 131 & 56.2 & 56.2 & 56.2 \\
\hline 28 - 37 years & 44 & 18.9 & 18.9 & 75.1 \\
\hline 38 - 47 years & 25 & 10.7 & 10.7 & 85.8 \\
\hline 48 - 57 years & 23 & 9.9 & 9.9 & 95.7 \\
\hline 58 years or above & 10 & 4.3 & 4.3 & 100.0 \\
\hline \multicolumn{5}{|c|}{ Educational Level } \\
\hline Matric or O level & 25 & 10.7 & 10.7 & 10.7 \\
\hline Intermediate or A level & 51 & 21.9 & 21.9 & 32.6 \\
\hline Bachelor's Degree & 84 & 36.1 & 36.1 & 68.7 \\
\hline Master's Degree & 64 & 27.5 & 27.5 & 96.1 \\
\hline Above Master's Degree & 9 & 3.9 & 3.9 & 100.0 \\
\hline Total & 233 & 100.0 & 100.0 & \\
\hline
\end{tabular}

Table 2 displays the descriptive statistics of the participants' responses and showing the central tendency, dispersion, and distribution within the acceptable range.

Table 2. Descriptive Statistics of Responses

\begin{tabular}{|c|c|c|c|c|c|c|c|c|c|}
\hline & $\mathbf{Q I}$ & RTI & CFI & PI & $\begin{array}{c}\text { WMP } \\
\text { (Overall) }\end{array}$ & IVS & RTC & RTFD & CS \\
\hline Valid & 233 & 233 & 233 & 233 & 233 & 233 & 233 & 233 & 233 \\
\hline Missing & 0 & 0 & 0 & 0 & 0 & 0 & 0 & 0 & 0 \\
\hline Mean & 3.0541 & 3.2604 & 2.7868 & 3.0501 & 3.0378 & 2.8340 & 3.0483 & 2.9903 & 2.7811 \\
\hline $\begin{array}{l}\text { Std. Error of } \\
\text { Mean }\end{array}$ & .06489 & .07128 & .05802 & .06529 & .05838 & .05939 & .06175 & .06181 & .05790 \\
\hline Median & 3.0000 & 3.6667 & 2.6667 & 3.0000 & 3.1833 & 2.8333 & 3.2500 & 3.2500 & 2.7500 \\
\hline -Mode & 2.40 & 4.00 & 3.00 & 4.00 & $3.40^{\mathrm{a}}$ & 3.00 & 3.75 & 3.75 & 3.00 \\
\hline $\begin{array}{c}\text { Std. } \\
\text { Deviation }\end{array}$ & .99047 & 1.08804 & .88563 & .99658 & .89114 & .90662 & .94263 & .94354 & .88379 \\
\hline Variance & .981 & 1.184 & .784 & .993 & .794 & .822 & .889 & .890 & .781 \\
\hline
\end{tabular}




\begin{tabular}{ccccccccccc}
\hline Skewness & .027 & -.405 & .350 & -.276 & -.276 & .036 & -.211 & -.072 & .223 \\
\hline $\begin{array}{c}\text { Std. Error of } \\
\text { Skewness }\end{array}$ & .159 & .159 & .159 & .159 & .159 & .159 & .159 & .159 & .159 \\
\hline Kurtosis & -1.042 & -.972 & -.093 & -.847 & -.926 & -.632 & -.991 & -.963 & -.460 \\
\hline $\begin{array}{c}\text { Std. Error of } \\
\text { Kurtosis }\end{array}$ & .318 & .318 & .318 & .318 & .318 & .318 & .318 & .318 & .318 \\
\hline Range & 4.00 & 4.00 & 4.00 & 4.00 & 4.00 & 4.00 & 4.00 & 4.00 & 4.00 \\
\hline Minimum & 1.00 & 1.00 & 1.00 & 1.00 & 1.00 & 1.00 & 1.00 & 1.00 & 1.00 \\
\hline Maximum & 5.00 & 5.00 & 5.00 & 5.00 & 5.00 & 5.00 & 5.00 & 5.00 & 5.00 \\
\hline Sum & 711.60 & 759.67 & 649.33 & 710.67 & 707.82 & 660.33 & 710.25 & 696.75 & 648.00 \\
\hline
\end{tabular}

a. Multiple modes exist. The smallest value is shown

\subsection{Reliability \& Validity}

Table 3 displays the internal consistency of the items, measured in two stages (the pilot testing and the final testing) to check the reliability of the instrument used to gather the data from the sampled respondents. The internal consistency between the items against each construct, in both stages, was found reliable and thus the instrument was declared as reliable for the further process.

Table 3. Internal Consistency

Pilot Test $\mathrm{N}$ of Items Final Test $\mathrm{N}$ of Items

\begin{tabular}{ccccc}
\hline QI & .817 & 5 & .858 & 5 \\
\hline RTI & .814 & 3 & .842 & 3 \\
\hline CFI & .868 & 3 & .831 & 3 \\
\hline PI & .711 & 3 & .753 & 3 \\
\hline IVS & .745 & 6 & .763 & 6 \\
\hline RTC & .816 & 4 & .834 & 4 \\
\hline RTFD & .801 & 4 & .811 & 4 \\
\hline CS & .702 & 4 & .762 & 4 \\
\hline
\end{tabular}

The Sampling Adequacy was tested by employing KMO and Bartlett's Test using SPSS Statistics prior to testing the construct validity. Table 4 displays the output of such tests. 
Table 4. Sampling Adequacy

\section{KMO and Bartlett's Test}

\begin{tabular}{|c|c|c|}
\hline Kaiser-Meyer-Olkin Measure & f Sampling Adequacy & .897 \\
\hline \multirow{3}{*}{ Bartlett's Test of Sphericity } & Approx. Chi-Square & 2204.979 \\
\hline & $\mathrm{df}$ & 28 \\
\hline & Sig. & .000 \\
\hline
\end{tabular}

Principal Components Analysis (PCA) was employed using SPSS Statistics version 24 to test the Convergent Validity of the used constructs. Table 5 shows the output of PCA revealing that 8 constructs were extracted. The output of PCA reveals the constructs as valid for hypotheses testing.

Table 5. Convergent Validity

\begin{tabular}{|c|c|c|c|c|c|c|c|c|}
\hline \multicolumn{9}{|c|}{ Component Matrix } \\
\hline & & & & Compc & nents & & & \\
\hline & 1 & 2 & 3 & 4 & 5 & 6 & 7 & 8 \\
\hline QI1 & 0.629 & & & & & & & \\
\hline QI2 & 0.519 & & & & & & & \\
\hline QI3 & 0.575 & & & & & & & \\
\hline QI4 & 0.658 & & & & & & & \\
\hline QI5 & 0.521 & & & & & & & \\
\hline RTI1 & & 0.801 & & & & & & \\
\hline RTI2 & & 0.598 & & & & & & \\
\hline RTI3 & & 0.729 & & & & & & \\
\hline CFI1 & & & 0.691 & & & & & \\
\hline CFI2 & & & 0.561 & & & & & \\
\hline CFI3 & & & 0.641 & & & & & \\
\hline PI1 & & & & 0.398 & & & & \\
\hline PI2 & & & & 0.369 & & & & \\
\hline $\mathrm{PI} 3$ & & & & 0.751 & & & & \\
\hline IVS1 & & & & & 0.751 & & & \\
\hline IVS2 & & & & & 0.645 & & & \\
\hline
\end{tabular}




\begin{tabular}{|c|c|c|}
\hline IVS3 & 0.802 & \\
\hline IVS4 & 0.645 & \\
\hline IVS5 & 0.802 & \\
\hline IVS6 & 0.545 & \\
\hline RTC1 & 0.498 & \\
\hline RTC2 & 0.651 & \\
\hline RTC3 & 0.591 & \\
\hline RTC4 & 0.445 & \\
\hline RTFD1 & & 0.702 \\
\hline RTFD2 & & 0.822 \\
\hline RTFD3 & & 0.645 \\
\hline RTFD4 & & 0.561 \\
\hline CS1 & & 0.521 \\
\hline $\mathrm{CS} 2$ & & 0.598 \\
\hline CS3 & & 0.691 \\
\hline CS4 & & 0.519 \\
\hline
\end{tabular}

Extraction Method: Principal Component Analysis.

a. 8 components extracted.

Table 6 shows the correlation between the items used in the instrument.

Table 6. Correlation

\begin{tabular}{|c|c|c|c|c|c|c|}
\hline & & WMP & IVS & RTC & RTFD & CS \\
\hline \multirow{3}{*}{ WMP } & $\begin{array}{c}\text { Pearson } \\
\text { Correlation }\end{array}$ & 1 & & & & \\
\hline & Sig. (2-tailed) & & & & & \\
\hline & $\mathrm{N}$ & 233 & & & & \\
\hline \multirow{3}{*}{ IVS } & $\begin{array}{c}\text { Pearson } \\
\text { Correlation }\end{array}$ & $.830^{* *}$ & 1 & & & \\
\hline & Sig. (2-tailed) & .000 & & & & \\
\hline & $\mathrm{N}$ & 233 & 233 & & & \\
\hline \multirow{3}{*}{ RTC } & $\begin{array}{c}\text { Pearson } \\
\text { Correlation }\end{array}$ & $.841^{* *}$ & $.806^{* *}$ & 1 & & \\
\hline & Sig. (2-tailed) & .000 & .000 & & & \\
\hline & $\mathrm{N}$ & 233 & 233 & 233 & & \\
\hline
\end{tabular}




\begin{tabular}{ccccccc}
\hline \multirow{2}{*}{ RTFD } & $\begin{array}{c}\text { Pearson } \\
\text { Correlation }\end{array}$ & $.863^{* *}$ & $.814^{* *}$ & $.916^{* *}$ & 1 & \\
\cline { 2 - 7 } & Sig. (2-tailed) & .000 & .000 & .000 & & \\
\cline { 2 - 7 } $\mathrm{N}$ & 233 & 233 & 233 & 233 & \\
\hline \multirow{2}{*}{$\mathrm{CS}$} & $\begin{array}{c}\text { Pearson } \\
\text { Correlation }\end{array}$ & $.820^{* *}$ & $.838^{* *}$ & $.778^{* *}$ & $.805^{* *}$ & 1 \\
\cline { 2 - 7 } & Sig. (2-tailed) & .000 & .000 & .000 & .000 & \\
\cline { 2 - 7 } & $\mathrm{N}$ & 233 & 233 & 233 & 233 & 233 \\
\hline
\end{tabular}

\subsection{Inferential Analysis}

\subsubsection{Testing Hypotheses}

Prior to testing the hypothesis, the significant variables were found for Warehousing Management Performance. Table 7 shows the significance of each variable used to measure the Warehousing Management Performance. The significance of such variables was measured by employing One Sample Test using SPSS version 24 and the acceptable score (test value) was set as $2.5=50$ per cent. Since all variables (including QI, RTI, CF, and PI) are significant, the research merged all of them into a main variable labelling it as Warehousing Management Performance (WMP).

Table 7. One Sample Test

\begin{tabular}{cccccccc}
\hline $\begin{array}{c}\text { Test Value } \\
=2.5\end{array}$ & $\mathrm{~T}$ & Df & $\begin{array}{c}\text { Sig. } \\
(2 \text {-tailed })\end{array}$ & Mean & $\begin{array}{c}\text { Mean } \\
\text { Difference }\end{array}$ & $\begin{array}{c}\text { Std. } \\
\text { Deviation }\end{array}$ & $\begin{array}{c}\text { Std. Error } \\
\text { Mean }\end{array}$ \\
\hline QI & 8.539 & 232 & .000 & 3.0541 & .55408 & .99047 & .06489 \\
\hline RTI & 10.667 & 232 & .000 & 3.2604 & .76037 & 1.08804 & .07128 \\
\hline CF & 4.944 & 232 & .000 & 2.7868 & .28684 & .88563 & .05802 \\
\hline PI & 8.425 & 232 & .000 & 3.0501 & .55007 & .99658 & .06529 \\
\hline
\end{tabular}

Multiple leaner regression was run using SPSS package version 24 to test the hypotheses of the current study. Table 8 shows the overall impact of independent variables on the dependent variable. The $\mathrm{R}$ value shows the multiple correlation coefficient (.900) depicting that having change in the independent variables (CS, RTC, IVS, and RTFD) the dependent variable (WMP) changes either negatively or positively. The R2 value in second row shows the coefficient of determination $(.810=81$. per cent), which is the proportion of variance brought by the independent variables in the dependent variable. 
Table 8. Model Summary

\begin{tabular}{ccccc}
\hline Model & $\mathrm{R}$ & R Square & Adjusted R Square & Std. Error of the Estimate \\
\hline 1 & $.900^{\mathrm{a}}$ & .810 & .807 & .39168 \\
\hline
\end{tabular}

a. Predictors: (Constant), CS, RTC, IVS, RTFD

The ANOVA table (Table 9) shows the fitness of the model to regress the model. The F ratio shows that the independent variables statistically significantly predict the dependent variable, $\mathrm{F}(4,228)=243.230, \mathrm{p}<.000$. This can be interpreted in other words as the regression model is a good fit of the data.

Table 9. ANOVA

\begin{tabular}{ccccccc}
\hline \multirow{2}{*}{ Model } & $\begin{array}{c}\text { Sum of } \\
\text { Squares }\end{array}$ & df & $\begin{array}{c}\text { Mean } \\
\text { Square }\end{array}$ & F & Sig. \\
\hline \multirow{2}{*}{1} & Regression & 149.258 & 4 & 37.315 & 243.230 & $.000^{\mathrm{b}}$ \\
\cline { 2 - 7 } & Residual & 34.978 & 228 & .153 & & \\
\cline { 2 - 7 } & Total & 184.237 & 232 & & & \\
\hline
\end{tabular}

a. Dependent Variable: WMP

b. Predictors: (Constant), CS, RTC, IVS, RTFD

The coefficient table (table 10) displays the impact of each individual independent variable on the dependent variable (WMP). The following equation was designed for the present study: The predicted $\mathrm{WMP}=.323+(.227 \times \mathrm{IVS})+(.159 \times \mathrm{RTC})+(.329 \times \mathrm{RTFD})+(.217 \times \mathrm{CS})$

It the light of the output of the coefficient table, it is safe to state that the variables CS, RTC, IVS, and RTFD added statistically significant and positive impact to the predicted variable WMP, $p>.05$.

Table 10. Coefficients

\begin{tabular}{|c|c|c|c|c|c|c|c|c|}
\hline \multirow{2}{*}{\multicolumn{2}{|c|}{ Model }} & \multicolumn{2}{|c|}{$\begin{array}{l}\text { Unstandardized } \\
\text { Coefficients }\end{array}$} & \multirow{2}{*}{$\begin{array}{c}\begin{array}{c}\text { Standardized } \\
\text { Coefficients }\end{array} \\
\text { Beta }\end{array}$} & \multirow[t]{2}{*}{$\mathrm{t}$} & \multirow[t]{2}{*}{ Sig. } & \multicolumn{2}{|c|}{$\begin{array}{c}\text { Collinearity } \\
\text { Statistics }\end{array}$} \\
\hline & & B & Std. Error & & & & Tolerance & VIF \\
\hline & (Constant) & .323 & .091 & & 3.537 & .000 & & \\
\hline & IVS & .227 & .059 & .231 & 3.852 & .000 & .232 & 4.307 \\
\hline \multirow[t]{3}{*}{1} & RTC & .159 & .070 & .169 & 2.267 & .024 & .150 & 6.647 \\
\hline & RTFD & .329 & .074 & .348 & 4.466 & .000 & .137 & 7.306 \\
\hline & CS & .217 & .058 & .215 & 3.734 & .000 & .252 & 3.973 \\
\hline
\end{tabular}

a. Dependent Variable: WMP

Table 11 reveals the summary of all hypotheses displaying that the present study rejected all 
of the null hypotheses. In the light of results, it is safe to state that the sampled population perceived that the e-Logistics procedures such as Information Visibility and Sharing, Real Time Communication, Real Time Forecasting Decision, and Cost Savings increase the overall performance of Warehousing Management in various aspects including Quality Indicator, Response Time Indicator, Cost/Financial Indicator, and Productivity Indicator.

Table 11. Summary of Hypotheses.

\begin{tabular}{llll}
\hline No. & \multicolumn{1}{c}{ Hypotheses } & Sig value & Status \\
\hline $\mathbf{H}_{\mathbf{1}}$ & $\begin{array}{l}\text { Internal Organizational Support does not impact on Electronic Procurement } \\
\text { Intentions (EPI) - e-recruitment intention }\end{array}$ & .023 & Rejected \\
\hline $\mathbf{H}_{\mathbf{2}}$ & Integration with Suppliers' Electronic Systems does not impact on EPI & .862 & $\begin{array}{c}\text { Failed } \\
\text { to reject }\end{array}$ \\
\hline $\mathbf{H}_{3}$ & Supplier Willingness does not impact on EPI & .000 & Rejected \\
\hline $\mathbf{H}_{4}$ & Perceived Improvements to Purchasing Tasks do not impact on EPI & .000 & Rejected \\
\hline & & & Failed \\
$\mathbf{H}_{5}$ & Supplier Pressure does not impact on EPI & 997 & to reject \\
\hline
\end{tabular}

\section{Discussion and Conclusion}

Chapter five, discusses the results in according with the literature review. It provides conclusion of the study, recommend future recommendations and states the limitations, which the researcher has faced during the study.

\subsection{Discussion and Conclusion}

For producing answers to the proposed research questions, four hypotheses were created. The first hypothesis states that "Information visibility and sharing in e-logistics does not impact on warehousing management performance at English Biscuit Manufacturing" The results rejected the first null hypothesis. The variable warehousing management performance was significantly affected by the variable Information visibility and sharing in e-logistics at English Biscuit Manufacturing. The results support the findings of previous researches. Omar, Ramayah, Sang, \& Siron, (2010) states that information sharing through e commerce in logistics aid in the performance of warehouses.

The hypothesis Real time communication in e-logistics does not impact on warehousing management performance at English Biscuit Manufacturing was developed for our second 
research question. Results of the study rejects the second null hypothesis. According to the results Real time communication in e-logistics graetly impact on warehousing management performance at English Biscuit Manufacturing. Atieh, Kaylani, Al-abdallat, Qaderi, Ghoul, Jaradat, \& Hdairis (2016) defines real time communication as an indicator for the performance of warehouse. The organizations must function to establish strong communication.

The third research question of the study was to determine the impact of Real time forecasting decision in e-logistics on warehousing management performance at English Biscuit Manufacturing. The hypothesis made to answer this question states that real time forecasting decision in e-logistics does not impact on warehousing management performance at English Biscuit Manufacturing. The analysis and testing of third research hypothesis indicates significant relationships between the variable real time forecasting decision in e-logistics and warehousing management performance at English Biscuit Manufacturing. Therefore, the third null hypothesis has also been rejected. Christopher, M. (2017) provided an evidence to this result stating that real time forecasting decision in e-logistics is crucial and its plays a leading role in increase the performance level of warehouses. The Real time forecasting decision in e-logistics is significantly related with warehousing management performance/

The fourth null hypothesis of the study was developed in answer to the fourth research question. The null hypothesis indicates no relation between cost savings in e-logistics and infrastructure and warehousing management performance at unilever in Pakistan. The results also reject the fourth null hypothesis. The study has established significant influence of cost savings in e-logistics warehousing management performance. Kawa, A. (2017) supports the current results. In his research, he has explained cost saving practices through e-commerce. According to him, lots of time and cost can be saved with the use of e-commerce in logistics

\subsection{Limitations}

This research is limited to the soft drink companies of Karachi and consist a limited sample due to the shortage of time. The results need to be more generalizable which can be done by enhancing the scope of the study and taking more number of respondents as a sample. This research also limits within Karachi only due to the accessibility issues faced by the researcher. The data including larger samples from different organizations all over Pakistan would be beneficial to develop a clearer picture regarding the factors influencing e-procurement practice in Pakistan.

\section{Acknowledgement}

Above all I want to thank to Almighty "ALLAH" who is most tolerant and kind and who makes me ready to set up this research study.

I generously appreciate my research supervisor, Sir Muhammad Asim, whose support and assistance from the beginning step to the last level permitted me to build up an understanding of the methodology of conducting research and authorised me to build up a comprehension of 
the approach of leading research exploration.

Also, I would like to express my gratitude to my parents, my fellow students for their support and patience, for keeping me motivated.

My research work has benefited from the insightful direction of numerous colleagues, teachers, family members and more numerous than I can fully acknowledge here. I would like to acknowledge those who contributed in the occasions that I conducted discussions to get formal feedback on my research topic that is "Impact of E-Logistics on Warehousing Management Performance at English Biscuit Manufacturing”.

Lastly, I offer my respects and endowments to all those who trusted and supported me in any regard during the fulfilment of the research study.

\section{References}

Arvis, J. F., Ojala, L., Wiederer, C., Shepherd, B., Raj, A., Dairabayeva, K., \& Kiiski, T. (2018). Connecting to Compete 2018: Trade Logistics in the Global Economy. World Bank.

Atieh, A. M., Kaylani, H., Al-abdallat, Y., Qaderi, A., Ghoul, L., Jaradat, L., \& Hdairis, I. (2016). Performance improvement of inventory management system processes by an automated warehouse management system. Procedia Cirp, 41, 568-572.

Bogale, T. (2016). Assessment of warehouse performance: a case of Ethiopian trading enterprise (Masters of Art in Logistics and Supply Chain Management). Addis Ababa University School of Business and Economics.

Christopher, M. (2017). New directions in logistics. In Global logistics and distribution planning (pp. 47-58). Routledge.

Fichtinger, Johannes, Jörg M. Ries, Eric H. Grosse, \& Peter Baker. (2015). Assessing the environmental impact of integrated inventory and warehouse management. International Journal of Production Economics, 170, 717-729.

Giuffrida, M., Mangiaracina, R., Perego, A., \& Tumino, A. (2017). Cross-border B2C e-commerce to Greater China and the role of logistics: a literature review. International Journal of Physical Distribution \& Logistics Management, 47(9), 772-795.

Kawa, A. (2017). Fulfillment service in e-commerce logistics. LogForum, 13.

Mangiaracina, R., Marchet, G., Perotti, S., \& Tumino, A. (2015). A review of the environmental implications of $\mathrm{B} 2 \mathrm{C}$ e-commerce: a logistics perspective. International Journal of Physical Distribution \& Logistics Management, 45(6), 565-591.

Omar, R., Ramayah, T., Lo, M. C., Sang, T. Y., \& Siron, R. (2010). Information sharing, information quality and usage of information technology (IT) tools in Malaysian organizations. African Journal of Business Management, 4(12), 2486-2499.

Xu, S. X., Cheng, M., \& Huang, G. Q. (2015). Efficient intermodal transportation auctions 
for B2B e-commerce logistics with transaction costs. Transportation Research Part B: Methodological, 80, 322-337.

Yu, Y., Wang, X., Zhong, R. Y., \& Huang, G. Q. (2016). E-commerce logistics in supply chain management: Practice perspective. Procedia Cirp, 52, 179-185.

Yu, Y., Wang, X., Zhong, R. Y., \& Huang, G. Q. (2016). E-commerce logistics in supply chain management: Practice perspective. Procedia Cirp, 52, 179-185.

Yu, Y., Wang, X., Zhong, R. Y., \& Huang, G. Q. (2017). E-commerce logistics in supply chain management: Implementations and future perspective in furniture industry. Industrial Management \& Data Systems, 117(10), 2263-2286.

Zhang, M., Pratap, S., Huang, G. Q., \& Zhao, Z. (2017). Optimal collaborative transportation service trading in B2B e-commerce logistics. International Journal of Production Research, 55(18), 5485-5501.

\section{Copyright}

Copyright for this article is retained by the author(s), with first publication rights granted to the journal.

This is an open-access article distributed under the terms and conditions of the Creative Commons Attribution license (http://creativecommons.org/licenses/by/4.0/). 